\title{
STUDI SIFAT TERMAL BATUAN DAERAH LAPANGAN PANAS BUMI WAY RATAI BERDASARKAN PENGUKURAN METODE KONDUKTIVITAS TERMAL
}

\author{
Ryan Donovan $^{* 1}$, Karyanto ${ }^{1}$, Ordas Sewanto ${ }^{1}$ \\ ${ }^{1}$ Jurusan Teknik Geofisika, Fakultas Teknik, Universitas Lampung \\ Jln. Prof. Dr. Soematri Brojonegoro, No.1 Bandar Lampung 35145, Lampung \\ Jurusan Teknik Geofisika, FT UNILA \\ e-mail:**1onovanr61@gmail.com
}

\begin{abstract}
ABSTRAK
Telah dilakukan penelitian pada daerah lapangan panas bumi Way Ratai dengan pengukuran metode konduktivitas termal. Data konduktivitas termal digunakan untuk memetakan persebaran batuan menghantarkan panas secara konduksi dalam sistem panas bumi. Hasil data pengukuran dengan metode konduktivitas termal pada daerah lapangan panas bumi Way Ratai berupa data $\mathrm{k}$ (konduktivitas), Rt (resistivitas termal), dan $\mathrm{T}$ (suhu). Nilai data konduktivitas yang terukur di lapangan panas bumi tersebut berkisar $0.056-0.664 \mathrm{~W} / \mathrm{mK}$, nilai data resistivitas termal yang terukur berkisar $1.344-17.527 \mathrm{mK} / \mathrm{W}$, dan nilai suhu yang terukur berkisar 22.68$52.59^{\circ} \mathrm{C}$. Tinggi rendahnya nilai konduktivitas termal batuan dipengaruhi oleh beberapa faktor, yaitu struktur geologi yang ada di lapangan seperti sesar normal dan kelurusan-kelurusan (lineaments), keberadaan alterasi, serta manifestasi air panas atau tempat keluarnya uap panas dari fumarol.
\end{abstract}

\begin{abstract}
Research on Way Ratai geothermal field has been done by measuring the thermal conductivity method. The thermal conductivity data is used to generate a map of the dispersion of heat conductively conductive rocks in the geothermal system. The result of measurement by thermal conductivity method in Way Ratai geothermal field is data of $\mathrm{k}$ (conductivity), Rt (thermal resistivity), and $\mathrm{T}$ (temperature). The value of the measured conductivity data in the geothermal field has range between $0.056-0.664 \mathrm{~W} / \mathrm{mK}$, the measured thermal resistivity value has range between $1.344-17.527 \mathrm{mK} / \mathrm{W}$, and the measured temperature value is between $22.68-52.59^{\circ} \mathrm{C}$. The difference value of rock's thermal conductivity is influenced by several factors, which is the existing geological structures in the field such as normal faults and lineaments, the presence of alteration, also the manifestation zone of hot water or hot vapor that caused from fumaroles.
\end{abstract}

Keywords - thermal conductivity, manifestation, geothermal.

\section{PENDAHULUAN}

\subsection{Latar Belakang}

Batuan memiliki berbagai sifat fisika, salah satunya adalah sifat termal. Sifat termal pada batuan meliputi konduksi, konveksi, dan lain-lain. Pada penelitian ini sifat termal yang digunakan adalah konduktivitas. Konduktivitas atau keterhantaran termal $(k)$ adalah suatu besaran intensif bahan yang menunjukkan kemampuannya untuk menghantarkan panas. Setiap batuan memiliki tingkat konduktivitas yang berbeda-beda tergantung dari struktur batuannya.

Lokasi daerah penelitian berada di daerah panas bumi Way Ratai, Kecamatan Padang Cermin, Kabupaten Pesawaran, Provinsi Lampung. Daerah lapangan panas bumi ini terdapat sumur-sumur air panas 
yang terdapat di permukaan mempunyai suhu yang relatif tinggi $\left(80^{\circ} \mathrm{C}-90^{\circ} \mathrm{C}\right)$ yang berada di beberapa tempat. Sumur tersebut merupakan manifestasi permukaan dari suatu sistem panas bumi yang sampai saat ini belum banyak di-eksplorasi oleh para peneliti (Karyanto, 2003).

Menurut Karyanto dan Haerudin (2013), panas merupakan parameter yang dominan pada daerah panas bumi, sehingga perlu dilakukan penelitian di daerah panas bumi Way Ratai. Penelitian metode konduktivitas termal digunakan untuk melihat kemampuan suatu batuan untuk menghantarkan panas dengan cara konduksi.

\subsection{Tujuan Penelitian}

Adapun tujuan penelitian ini adalah sebagai berikut :

1. Memetakan persebaran nilai
konduktivitas termal batuan.
2. Menganalisis sebaran nilai
konduktivitas termal batuan di
lapangan panas bumi Way Ratai.

3. Menentukan faktor-faktor yang mempengaruhi nilai dari konduktivitas termal batuan.

\section{TINJAUAN PUSTAKA}

\subsection{Letak dan Lokasi Penelitian}

Letak dan lokasi penelitian terletak pada lapangan panas bumi Way Ratai, Kecamatan Padang Cermin, Kabupaten Pesawaran, Provinsi Lampung. Secara geografis, Kabupaten Pesawaran terletak pada koordinat $5,12^{\circ}-5,84^{\circ} \mathrm{LS}$ dan $104,92^{\circ}-105,34^{\circ} \mathrm{BT}$.

\subsection{Geologi \& Stratigrafi Lokal}

Secara umum daerah lapangan panas bumi Way Ratai berada pada peta geologi lokal lapangan panas bumi Way Ratai yang memiliki dua gunung api yang saling berdekatan, yakni Gunung Ratai dan Gunung Betung.

Stratigrafi lengkap lapangan panas bumi Way Ratai dikelompokkan menjadi empat kelompok, yaitu:

1. Batuan Tersier.

batuan Tersier di sekitar daerah panas bumi Way Ratai dikenal sebagai batuan sedimen dari Formasi Ratai, disusun oleh konglomerat, batupasir, breksi lahar dan batulempung yang kadangkala berasosiasi dengan tuf andesit.

2. Batuan Vulkanik Pra Erupsi Gunung Betung dan Ratai.

Kelompok batuan vulkanik dari yang lebih tua ke muda adalah batuan Vulkanik Gebang (GV), Ignimbirit Gebang (GI), Aliran Lava Gebang (GL), Endapan Debris (ED), dan Banjarmerger Vulkanik (BV). Batuan vulkanik pra erupsi ini secara stratigrafi terletak diatas batuan sedimen Tersier.

3. Batuan Vulkanik Erupsi Gunung Betung dan Ratai.

Batuan vulkanik Kuarter dierupsikan menjadi dua sumber erupsi, yaitu erupsi Gunung Betung dan Ratai di dasar Kaldera Gebang. Adapun stratigrafi dari kedua sumber erupsi gunung ini adalah satuan BL1, RL1, BL2, RL2, BL3, RL3, RJP, Bap1, Rap1, Bap2, Rap2, BL4, RL4, BL5, RL5, BL6, RL6, BL7, RL7, BL8, RL8, RES, BL9, RL9, BKS, RL10, BL10, BL11, RL11, BKL, dan RL12.

4. Endapan Permukaan.

Adapun endapan permukaannya meliputi endapan Lahar (LH) dan endapan Aluvium (Al).

Adapun peta geologi lokal dan kolom stratigrafi lokal telah terlampir dalam gambar 1 dan gambar 2.

\subsection{Struktur Sesar}

Struktur sesar di lapangan panas bumi Way Ratai dan sekitarnya didominasi oleh struktur sesar berarah baratlaut-tenggara dan timurlaut-baratdaya yang diduga kuat 
sebagai sesar normal. Selain itu, di daerah penelitian terdapat kelurusan-kelurusan (lineaments) yang berarah utama timurlautbaratdaya dan baratlaut-tenggara (Gafoer dkk, 1993).

\subsection{Geomorfologi}

Morfologi Way Ratai dan sekitarnya dikelompokkan menjadi tujuh satuan morfologi, yaitu morfologi kubah lava, perbukitan bertekstur kasar, perbukitan bertekstur halus, perbukitan tua, pedataran bergelombang lemah, pedataran landai, dan perbukitan terisolir (Gafoer dkk, 1993).

\section{TEORI DASAR}

\subsection{Sistem Panas Bumi}

Secara umum panas bumi merupakan suatu bentuk energi panas yang tersimpan dalam batuan di bawah permukaan bumi dan fluida yang terkandung di dalamnya. Sementara sistem panas bumi memiliki pengertian yaitu suatu sistem yang memungkinkan terjadinya fluida dari daerah meteoric recharge ke dalam reservoar yang berada di atas sumber panas (Torkis, 2012).

Suatu daerah dikatakan memiliki sistem panas bumi jika memiliki beberapa komponen penting (Suharno, 2013) sebagai berikut:

- Sumber panas (heat source).

Sumber panas pada sistem panas bumi berasal dari intrusi batuan beku, dapur magma atau gradien temperatur. Sumber panas yang berasal dari intrusi batuan beku, diperkirakan terdapat pada kedalaman 2-5 km dan biasanya berada pada daerah gunungapi. Komposisi intrusi bisa granit atau gabro, tapi yang umum adalah diorit (Basid dkk, 2014). Sedangkan sumber panas yang berasal dari gradien temperatur biasa terdapat pada daerah lempeng tektonik aktif. Sumber panas mengalirkan panas secara konveksi dan konduksi.

- Batuan reservoar (permeable rock).

Reservoar panas bumi merupakan formasi batuan dibawah permukaan yang mampu menyimpan dan mengalirkan fluida termal (uap dan atau air panas). Umumnya, batuan reservoar memiliki prosositas dan permeabilitas yang baik sehingga fluida dapat terakumulasi untuk dipanaskan oleh sumber panas. Secara umum reservoar panas bumi yang produktif harus memiliki porositas rendah, konduktivitas termal dan permeabilitas yang tinggi, ukuran volume cukup besar, suhu tinggi, kandungan fluida yang cukup, dan kandungan silika pada batuan reservoarnya (Suharno, 2009).

- Batuan penutup (caprock).

Caprock pada sistem panas bumi berguna untuk menjaga agar panas yang berasal dari reservoar tidak keluar ke permukaan. Batuan penutup memiliki karakteristik yaitu permeabilitas yang rendah, tebal, dan berada di atas reservoar. Pada umumnya batuan penutup berupa clay, sering terjadi proses alterasi hidrotermal yang disebabkan oleh interaksi fluida dan aliran panas saat melewati batuan sehingga dapat menjadi indikator adanya sistem panas bumi pada suatu daerah (Riri, 2009).

- Struktur geologi

Struktur geologi bawah permukaan bumi merupakan salah satu komponen utama suatu sistem panas bumi, seperti adanya patahan, rekahan, dan ketidakselarasan. Manifestasi panas bumi muncul akibat dari zona lemah patahan atau sesar (Santoso, 2004).

\subsection{Sifat Batuan Panas Bumi}

Sebagian besar reservoar panas bumi terdapat pada batuan vulkanik dengan aliran utama melalui rekahan. Seperti 
halnya di perminyakan, sifat batuan yang penting menerangkan sifat batuan reservoar panas bumi adalah porositas, permeabilitas dan densitas batuan. Beberapa parameter lain yang penting untuk menerangkan sifat batuan reservoar panas bumi adalah panas spesifik dan konduktivitas panas (Saptadji, 2002).

\subsection{Konduktivitas Termal}

Konduktivitas panas adalah sifat termal suatu benda untuk merambatkan panas dalam suatu unit waktu melalui luas penampang tertentu yang diakibatkan oleh adanya perbedaan suhu (Jangam dan Mujumdar, 2010). Konduktivitas termal mengindikasikan seberapa cepat panas dalam reservoar mengalir sampai ke permukaan bumi. Tinggi rendahnya nilai konduktivitas termal batuan menentukan potensi reservoar dari panas bumi sebagai energi panas bumi (Endovani, 2016). Menurut Raina (1993), nilai konduktivitas batuan sekitar $0,05 \mathrm{~W} / \mathrm{m}^{\circ} \mathrm{C}$ sampai 3,0 $\mathrm{W} / \mathrm{m}^{\circ} \mathrm{C}$. Pada tabel 1 merupakan tabel nilai konduktivitas termal beberapa jenis batuan.

\subsection{Hubungan Dasar Perpindahan Panas Secara Konduksi}

Hubungan dasar untuk perpindahan panas dengan cara konduksi dikemukakan oleh ilmuwan Prancis, J.B.J Fourier. Hubungan ini menyatakan bahwa laju aliran panas dengan cara konduksi dalam suatu bahan sama dengan hasil kali dari tiga buah besaran, yaitu:

a. Konduktivitas panas bahan $(k)$.

b. Luas penampang melalui magma panas mengalir dengan cara konduksi, yang harus diukur secara tegak lurus terhadap arah aliran panas $(A)$.

c. Gradien suhu, yaitu laju perubahan suhu $\mathrm{T}$ terhadap jarak dalam arah aliran panas $\left(\frac{\partial T}{\partial Z}\right)$.
Adapun persamaannya dapat ditulis dalam persamaan (1) berikut ini:

$$
q_{k}=-k \cdot A \cdot \frac{\partial T}{\partial z} .
$$

dimana: $\quad q_{k}=$ laju aliran panas $(\mathrm{KJ} /$ det.W)

$k=$ konduktivitas $(\mathrm{W} / \mathrm{m} . \mathrm{K})$

$A=$ luas penampang $\left(\mathrm{m}^{2}\right)$

$\frac{\partial T}{\partial Z}=$ gradien suhu $(\mathrm{K})$

Hukum kedua Termodinamika menyatakan bahwa konduktivitas panas akan mengalir secara otomatis dari titik yang suhunya lebih tinggi menuju ke titik yang suhunya rendah, maka aliran konduksi panas $\mathrm{q}$ adalah positif, jika gradien suhu berharga negatif. Selain itu, arah kenaikan jarak $\mathrm{z}$ merupakan arah aliran konduksi panas positif.

Adapun ilustrasi arah aliran konduksi panas telah terlampir dalam gambar 3 .

Jika gradien suhu $\frac{\partial T}{\partial z}=1$, maka besarnya konduktivitas panas suatu bahan merupakan jumlah energi panas yang mengalir pada suatu bahan tiap satuan luas. Suatu bahan yang memiliki nilai konduktivitas panas besar merupakan penghantar yang baik dan sering disebut konduktor panas, sebaliknya suatu bahan yang memiliki nilai konduktivitas panas kecil merupakan penghantar panas yang buruk disebut isolator (Wahyono dkk, 2004).

\subsection{Transfer Panas}

Transfer panas (transfer oleh energi panas) dinyatakan oleh proses fisika, diantaranya:

- Konduksi

Pemindahan kalor yang terjadi pada dua benda padat yang berbeda temperatur dan terjadi kontak langsung.

- Konveksi

Terjadi dengan medium fluida (gas/zat cair) dengan dicirikan oleh ikut berpindahnya pembawa panas.

- Radiasi

Dimana panas ditransfer secara langsung tidak memerlukan medium, 
terpancar dalam bentuk gelombang elektromagnetik seperti cahaya atau gelombang radio.

Radiasi umumnya diabaikan untuk kondisi lithosperic, begitu juga konveksi diabaikan dikebanyakan proses. Oleh karena itu, untuk studi geofisika dari litosfer bumi, hanya konduksi yang penting dan sifat termal batuan paling substansial adalah konduktivitas termalnya (Chermak, 1982).

\subsection{Konduksi dan Konveksi Batuan}

Fluida panas bumi yang terkandung dalam reservoar hidrotermal berasal dari air permukaan, antara lain air hujan (air meteorik) yang meresap masuk ke bawah permukaan. Air tersebut akan masuk melalui rekahan-rekahan ke dalam batuan permeabel. Apabila disekitar batuan tersebut terdapat sumber panas, maka panas akan dirambatkan melalui batuan (secara konduksi) dan melalui fluida (secara konveksi) (Singarimbun dkk, 2014).

Perpindahan panas secara konduksi adalah perpindahan panas melalui bahan akibat adanya iteraksi atomik atau molekul penyusun batuan tersebut dalam mantel. Perpindahan panas secara konduksi terjadi ketika panas melewati batuan, pada sistem panas bumi panas secara konduksi dapat terjadi ketika perpindahan panas dari batuan sumber panas melalui lapisan batuan impermeable hingga ke permukaan.

Perpindahan panas secara konveksi pada dasarnya terjadi karena gaya apung air, karena gaya gravitasi selalu mempunyai kecenderungan untuk bergerak ke bawah, akan tetapi apabila air tersebut kontak dengan suatu sumber panas maka akan terjadi perpindahan panas sehingga temperatur air menjadi lebih tinggi dan air menjadi lebih ringan. Keadaan ini menyebabkan air yang lebih panas bergerak ke atas dan air yang lebih dingin bergerak turun ke bawah, sehingga terjadi sirkulasi air atau arus konveksi (Basid dkk, 2014).

\section{METODE PENELITIAN}

\subsection{Prosedur Penelitian}

Adapun prosedur dalam penelitian ini adalah sebagai berikut:

1. Akuisisi Data.

Sebelum melakukan akuisisi data, perlu adanya suatu desain survey penelitian. Desain survey dibuat dengan tipe grid dalam software ArcMap. Jarak antar titik adalah 400 meter, lalu pada saat akuisisi data disekitar manifestasi dibuat beberapa titik tambahan dengan jarak 100 meter guna melihat persebaran konduktivitasnya. Adapun desain survey penelitian telah terlampir dalam gambar 4 .

Dalam akuisisi data dilakukan pengukuran dalam kondisi sensor elektroda atau probe yang berada di bawah permukaan sedalam setengah meter dengan kondisi lubang tertutup. Usahakan agar kontak probe menyentuh dengan tanah permukaannya dan tidak gantung. Serta dihimbau untuk tidak memaksa memasukkan probe dengan keras ke dalam bawah permukaan karena dapat mengakibatkan probe patah. Lakukan pengukuran atau perekaman data selama 5 menit. Data pengukuran yang dihasilkan berupa nilai Rt (resistivitas), $k$ (konduktivitas), serta $T$ (suhu).

\section{Pengolahan Data.}

Setelah selesai melakukan proses akuisisi data, maka tahapan selanjutnya adalah proses pengolahan data. Pengolahan data dilakukan dengan memasukkan input data ke dalam Microsoft Excel yang berupa koordinat titik pengukuran X \& Y (berasal dari GPS garmin map 78s), nilai $R t$ (resistivitas), $k$ (konduktivitas), serta $T$ (suhu). Setelah diinput, lakukan grid data dalam software Surfer. Sehingga dapat 
dihasilkan empat buah peta, yaitu peta konduktivitas termal batuan dengan topografi daerah penelitian (data topografi dari peta DEM SRTM), peta konduktivitas termal batuan yang di-overlay dengan kondisi geologi lokal (tahap overlay dilakukan dalam software ArcMap), peta resistivitas termal, serta peta suhu daerah penelitiannya.

\section{Interpretasi Data.}

Setelah selesai melakukan proses pengolahan data, maka tahapan selanjutnya adalah proses interpretasi data atau analisis data. Interpretasi data dilakukan dengan melihat dari keempat hasil peta pengolahan data yang telah dibuat.

Pertama, peta konduktivitas termal batuan yang di-overlay dengan kondisi geologi lokalnya. Suatu daerah yang memiliki nilai konduktivitas termal yang tinggi diduga bahwa pada daerah tersebut berada di dekat manifestasi air panas yang kemunculannya berkaitan erat dengan kondisi geologi berupa sesar dan kelurusan-kelurusan (lineaments) untuk mengontrol daerah itu.

Kedua, peta konduktivitas termal batuan dengan topografinya. Kontur topografi suatu daerah umumnya digunakan untuk melihat bagaimana kondisi di lapangan saat melakukan akuisisi data. Semakin rapat suatu kontur topografi menyatakan daerah tersebut daerah yang curam, sedangkan semakin renggang suatu kontur topografi menyatakan daerah tersebut daerah landai.

Ketiga, peta suhu. Data suhu sangat diperlukan guna mendukung nilai konduktivitas termal batuan suatu daerah. Umumnya, nilai suhu dan konduktivitas termal adalah berbanding lurus. Jika nilai konduktivitas suatu titik menunjukkan nilai yang tinggi, maka nilai suhunya akan tinggi juga. Dan sebaliknya, jika nilai konduktivitas suatu titik menunjukkan nilai yang rendah, maka nilai suhunya akan rendah juga.
Keempat, peta resistivitas termal. Data resistivitas digunakan sebagai data pembanding dari nilai konduktivitas termal batuan. Secara teori dijelaskan bahwa nilai konduktivitas berbanding terbalik dengan nilai resistivitasnya. Jika nilai konduktivitas suatu titik menunjukkan nilai yang tinggi, maka nilai resistivitasnya akan rendah. Dan sebaliknya, jika nilai konduktivitas suatu titik menunjukkan nilai yang rendah, maka nilai resistivitasnya akan tinggi.

\subsection{Diagram Alir Penelitian}

Adapun diagram alir dalam pelaksanaan penelitian ini terlampir dalam gambar 5.

\section{HASIL DAN PEMBAHASAN}

\subsection{Peta Konduktivitas - Geologi Lokal}

Kemunculan suatu air panas daerah Way Ratai berkaitan erat dengan kenampakan geologi yang ada di lapangan berupa sesar normal yang mengontrol daerah penelitian yang berarah timurlautbaratdaya dan baratlaut-tenggara, dan juga kelurusan-kelurusan (lineaments) yang berarah utama sama dengan struktur sesarnya, yaitu timurlaut-baratdaya dan baratlaut-tenggara. Pada area penelitian tersusun atas batuan endapan lahar, ratai aliran piroklastik 1, ratai aliran piroklastik 2 , ratai lava 1 , ratai lava 2 , ratai lava 4 , ratai lava 5, dan yang terakhir ratai lava 7 .

Dari hasil peta konduktivitas - geologi lokal menunjukkan nilai konduktivitas yang tinggi berada tersebar di beberapa manifestasi air panas atau tempat keluarnya uap panas dari fumarol. Hal ini disebabkan oleh kandungan uap air di daerah panas sehingga menambah nilai konduktivitanya. Di samping itu, tanah atau top soil ini merupakan lapukan batuan yang mengalami proses alterasi terus menerus. Keberadaan alterasi berpengaruh terhadap nilai konduktivitas termal, hal ini 
dikarenakan batuan alterasi merupakan batuan yang memiliki konduktivitas yang baik. Pada daerah penelitian, daerah manifestasi air panas didominasi oleh kandungan silika sinter yang memiliki pengaruh yang tinggi terhadap nilai konduktivitas termalnya.

Kemudian terdapat nilai konduktivitas juga yang tinggi pada struktur geologi di daerah penelitian seperti sesar dan lineaments, hal ini dikarenakan pada area tersebut merupakan zona lemah yang dapat diterobos oleh fluida panas sehingga menambah nilai konduktivitasnya. Nilai konduktivitas juga meningkat apabila disaat pengukuran dekat dengan rawa atau adanya air atau batuan yang mengandung air, karena air bersifat konduktif.

Persebaran nilai konduktivitas termal batuan yang di-overlay dengan kondisi geologi lokalnya pada daerah penelitian dengan skala warna biru muda hingga tua menunjukkan nilai konduktivitas termal batuan yang rendah dan didominasi terletak pada litologi batuan ratai lava 1 (RL1), ratai lava 2 (RL2), ratai lava 7 (RL7), serta terdapat sisipan batuan berupa ratai aliran piroklastik 1 (Rap1) \& endapan lahar (LH) yang bernilai konduktivitas termal yang rendah juga. Untuk skala warna kuning hingga hijau menunjukkan nilai konduktivitas termal batuan yang menengah dan didominasi terletak pada litologi batuan ratai lava 4 (RL4), ratai lava 5 (RL5), serta terdapat sisipan batuan berupa ratai aliran piroklastik 2 (Rap2). Skala warna orange hingga merah tua tersebar di tujuh manifestasi air panas dan di kenampakan struktur geologi yang ada.

Adapun hasil peta konduktivitas yang di-overlay dengan geologi lokal telah terlampir dalam gambar 6.

\subsection{Peta Konduktivitas - Topografi}

Nilai hasil pengukuran konduktivitas termal batuan daerah lapangan panas bumi Way Ratai dan sekitarnya berkisar antara 0.056-0.644 W/mK. Pada peta kontur topografi menjelaskan bahwa semakin rapat suatu kontur topografi menyatakan daerah tersebut daerah curam, sedangkan semakin renggang suatu kontur topografi berarti daerah tersebut daerah landai. Topografi yang curam dominan berada di sebelah timurlaut dan timur daerah penelitian dan topografi yang landai dominan berada di sebelah tenggara dan selatan daerah penelitian. Pada dasarnya peta topografi digunakan untuk melihat medan sekitar daerah penelitian saat akuisisi data dilakukan.

Adapun hasil peta konduktivitas dengan topografi telah terlampir dalam gambar 7 .

\subsection{Peta Suhu}

Nilai hasil pengukuran suhu daerah lapangan panas bumi Way Ratai dan sekitarnya berkisar antara $22.68-52.59^{\circ} \mathrm{C}$. Data suhu digunakan sebagai data pendukung dari nilai konduktivitas termal di lapangan. Karena berdasarkan teori yang ada, bahwa nilai suhu dan konduktivitas berbanding lurus. Dari hasil peta suhu menunjukkan nilai suhu yang tinggi berada tersebar di beberapa manifestasi air panas daerah penelitian.

Persebaran nilai suhu batuan pada daerah penelitian dengan skala warna ungu, biru muda hingga tua menunjukkan nilai suhu batuan yang rendah dan didominasi terletak pada arah barat dan baratlaut daerah penelitian. Untuk skala warna hijau hingga kuning menunjukkan nilai suhu batuan yang menengah dan didominasi terletak pada arah timur, tenggara, dan selatan daerah penelitian. Dan skala warna orange hingga merah tua menunjukkan nilai suhu batuan yang tinggi di tujuh manifestasi air panas. Berdasarkan 
analisis suhu yang didapat, bisa dilihat bahwa peta konduktivitas termal batuan dengan suhunya mempunyai nilai yang relatif berbanding lurus satu sama lain.

Adapun hasil peta suhu telah terlampir dalam gambar 8.

\subsection{Peta Resistivitas Termal}

Nilai hasil pengukuran resistivitas termal daerah lapangan panas bumi Way Ratai dan sekitarnya berkisar antara 1.344 - $17.527 \mathrm{mK} / \mathrm{W}$. Peta resistivitas yang dimaksud disini bukanlah resistivitas listrik, melainkan resistivitas termal. Data resistivitas digunakan sebagai data pembanding dari nilai konduktivitas termal batuan. Secara teori, nilai konduktivitas termal dengan resistivitasnya memiliki hubungan berbanding terbalik. Jika nilai konduktivitas menunjukkan nilai yang tinggi maka nilai resistivitasnya akan rendah. Dan begitupun sebaliknya, jika nilai konduktivitas menunjukkan nilai yang rendah, nilai resistivitasnya akan tinggi.

Adapun hasil peta resistivitas termal telah terlampir dalam gambar 9.

\section{KESIMPULAN}

Adapun kesimpulan yang dapat diambil dalam penelitian metode konduktivitas termal batuan ini adalah sebagai berikut.

1. Berdasarkan hasil peta konduktivitasgeologi lokal dan peta konduktivitastopografi didapatkan nilai hasil pengukuran konduktivitas termalnya di daerah lapangan panas bumi Way Ratai dan sekitarnya berkisar 0.056-0.664 $\mathrm{W} / \mathrm{mK}$. Nilai konduktivitas termal tertinggi berada di manifestasi panas bumi Padok.

2. Berdasarkan hasil peta suhu didapatkan nilai hasil pengukuran suhu di daerah lapangan panas bumi Way Ratai dan sekitarnya berkisar $22.68-52.59^{\circ} \mathrm{C}$. Nilai suhu tertinggi berada di manifestasi panas bumi Padok.
3. Berdasarkan hasil peta resistivitas termal didapatkan nilai hasil pengukuran resisivitas termal di daerah lapangan panas bumi Way Ratai dan sekitarnya berkisar 1.344-17.527 $\mathrm{mK} / \mathrm{W}$. Nilai resistivitas termal tertinggi berada di titik J10.

4. Nilai konduktivitas termal batuan daerah lapangan panas bumi Way Ratai dan sekitarnya dipengaruhi oleh beberapa faktor, yaitu struktur geologi yang ada di lapangan seperti sesar normal dan kelurusan-kelurusan, keberadaan alterasi, serta manifestasi air panas atau tempat keluarnya uap panas dari fumarol.

\section{DAFTAR PUSTAKA}

Basid, A., Andrini, N., dan Arfiyaningsih, S., 2014. Pendugaan Reservoir Sistem Panasbumi Dengan Menggunakan Survey Geolistirk, Resistivitas, dan Self Potensial (Studi Kasus: Daerah Manifestasi Panasbumi di Desa Lombang, Kecamatan Batang-Batang, Sumenep). Jurnal Neutrino. Vol 7. No 1. Hal 61 dan 62.

Chermak., 1982. Conduction of Heat in Solids. Oxford University, Press.

Endovani, R., 2016. Analisis Konduktivitas Termal dan Porositas Silika Sinter Sumber Mata Air Panas di Sapan Maluluang, Kecamatan Alam Pauh Duo, Kabupaten Solok Selatan. Jurnal Fisika Unand. Vol 4. No 1. Hal. 65.

Gafoer, S., Amirudin., Mangga, A., dan Sidarto., 1993. Peta Geologi Lembar Tanjungkarang, Sumatera, Skala 1 : 250.000. Pusat Penelitian dan Pengembangan Geologi. Bandung.

Jangam, S.V., dan Mujumdar, A.S., 2010. Basic Concepts and Definitions. Drying of Foods, Vegetables, and Fruits. Singapore. 
Karyanto., 2003. Pencitraan Bawah Permukaan Daerah Panasbumi Way Ratai Lampung Dengan Metode Tahanan Jenis 2 Dimensi. Jurnal Sains Teknologi. Vol 9. No.3. Hal 55.

Karyanto., dan Haerudin, N., 2013. Interpretasi Kualitatif Suhu Permukaan di Potensi Panasbumi Way Ratai, Lampung. Prosiding Seminar Nasional Sains \& Teknologi $V$. Lembaga Penelitian Universitas Lampung. Bandar Lampung.

Raina, V. K., 1993. Concrete for Construction, Facts and Practic, Tata McGraw-Hill Publishing Company, Ltd., New Delhi.

Riri, O., 2009. Pemodelan Sistem Geothermal Daerah Sibayak Menggunakan Data Magnetotellurik dan Gravitasi. Skripsi. Universitas Indonesia. Depok.

Santoso, D., 2004. Catatan Kuliah "Eksplorasi Energi Geothermal". Institut Teknologi Bandung. Bandung.

Saptadji., N. 2002. . Catatan Kuliah "Teknik Panasbumi". Institut Teknologi Bandung. Bandung.

Singarimbun., A, Ehara, S.,dan Fujimitsu, Y. 2012. Estimation of Parameter Distribution and Injection Process in Geothermal Reservoir. International Journal of Energy and Environment. Issue 6. Volume 6.

Suharno., 2010. Pengembangan Prospek Panasbumi. Universitas Lampung. Bandar Lampung.

Suparno, S., 2009. A present from the heart of the earth. Jurnal Edisi Pertama. Universitas Indonesia. Depok.

Torkis, R., 2012. Analisa dan Pemodelan Struktur Bawah Permukaan Berdasarkan Metode Gayaberat di
Daerah Prospek Panas Bumi Gunung Lawu. Skripsi. Universitas Indonesia. Depok.

Wahyono, T., Wahyudi, dan Suyanto, I., 2004. Analisis Data Suhu, Konduktifitas, dan Aliran Panas Untuk Menafsir Struktur Bawah Permukaan Daerah Gedongsongo Beserta Potensinya. Prosiding Himpunan Ahli Geofisika Indonesia. Universitas Gadjah Mada. Yogyakarta. 

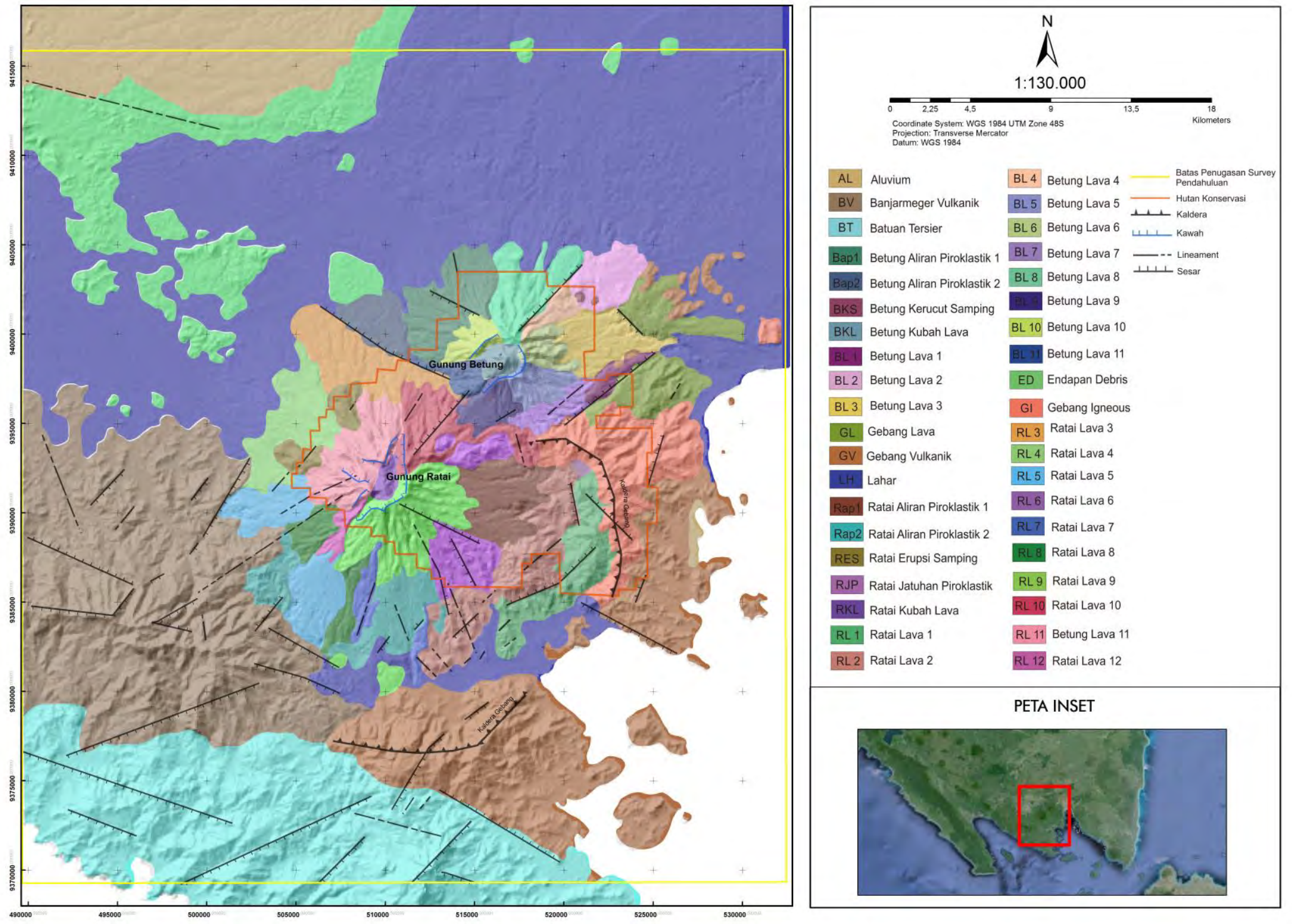

Gambar 1. Peta geologi lokal (modifikasi dari Gafoer dkk, 1993). 
KOLOM STRATIGRAFI (CORRELATION OF MAP UNITS)

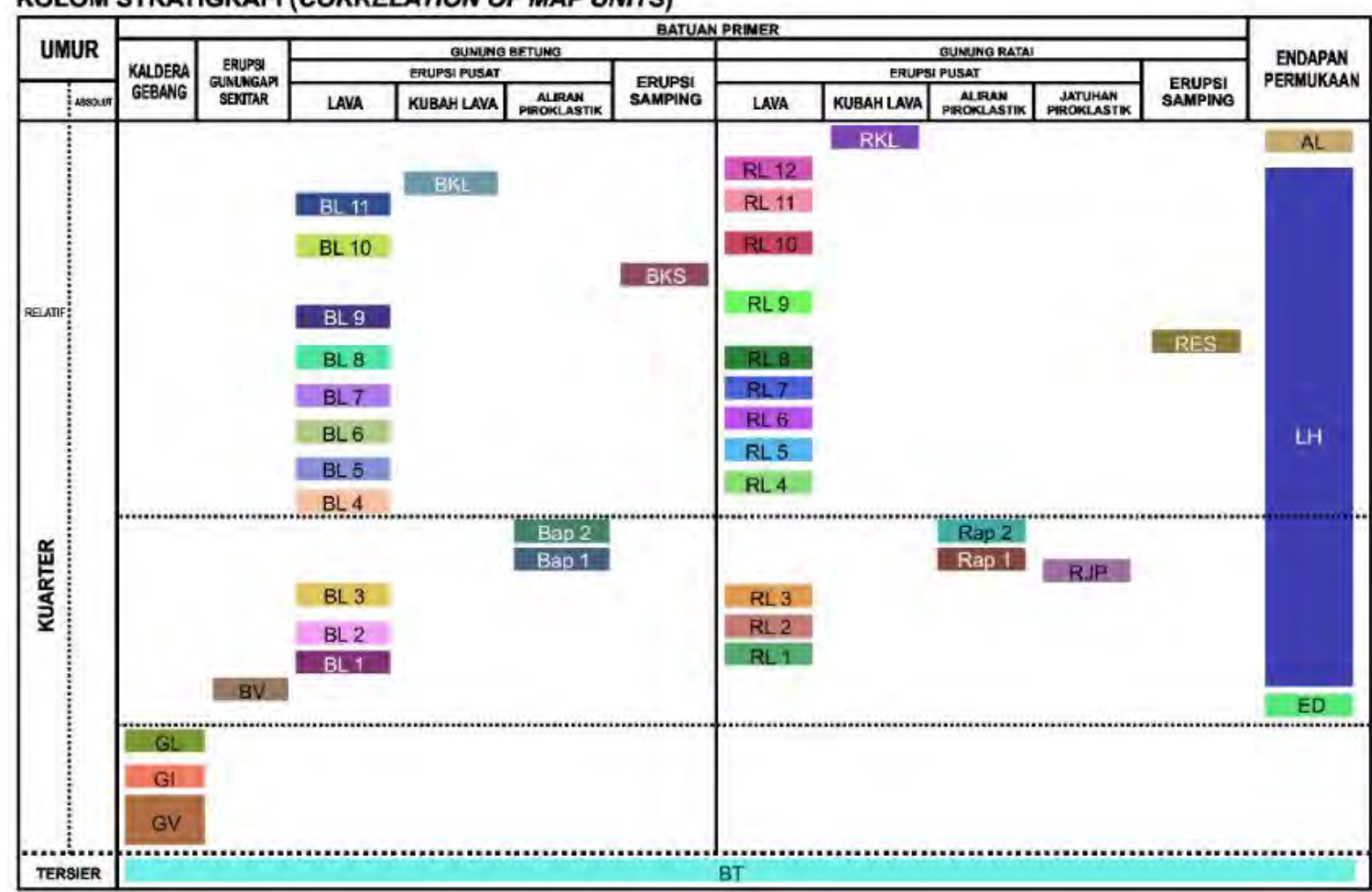

Gambar 2. Kolom stratigrafi lokal (modifikasi dari Gafoer dkk, 1993).

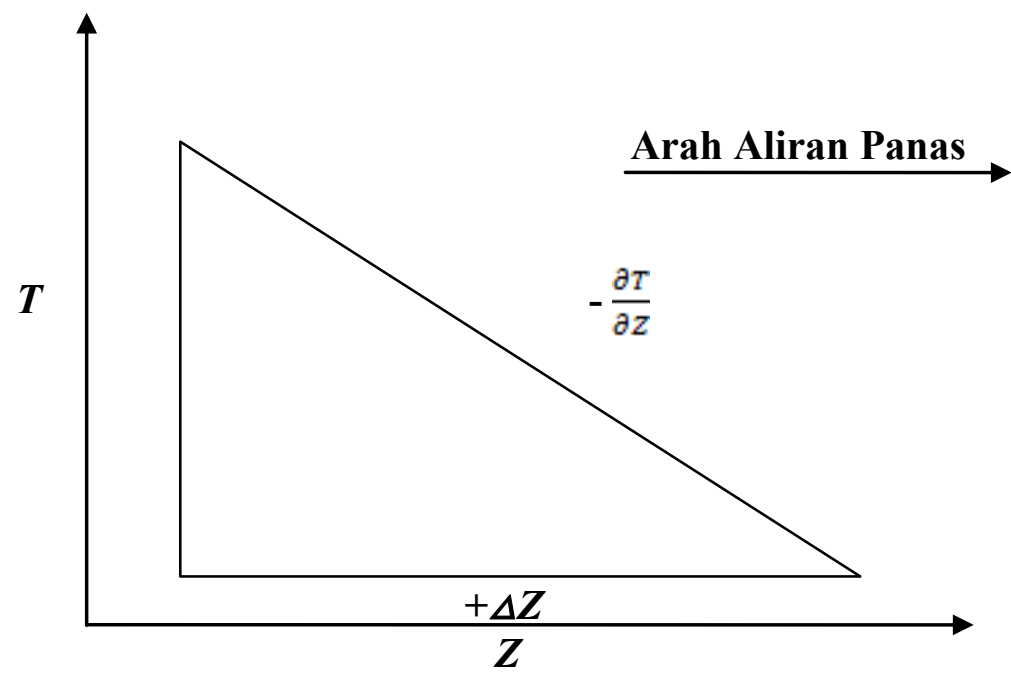

Gambar 3. Arah aliran konduksi panas. 


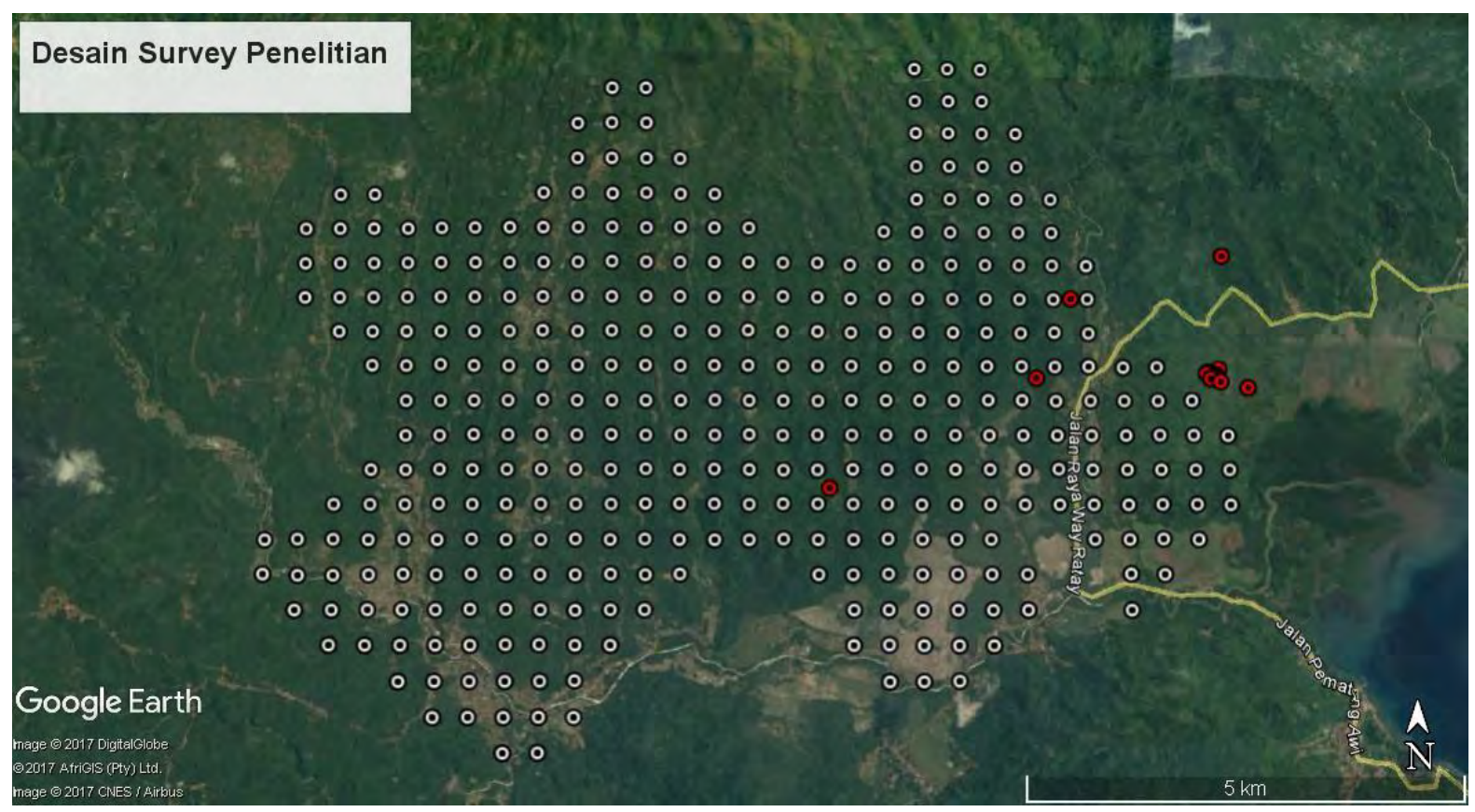

Gambar 4. Desain survey penelitian.

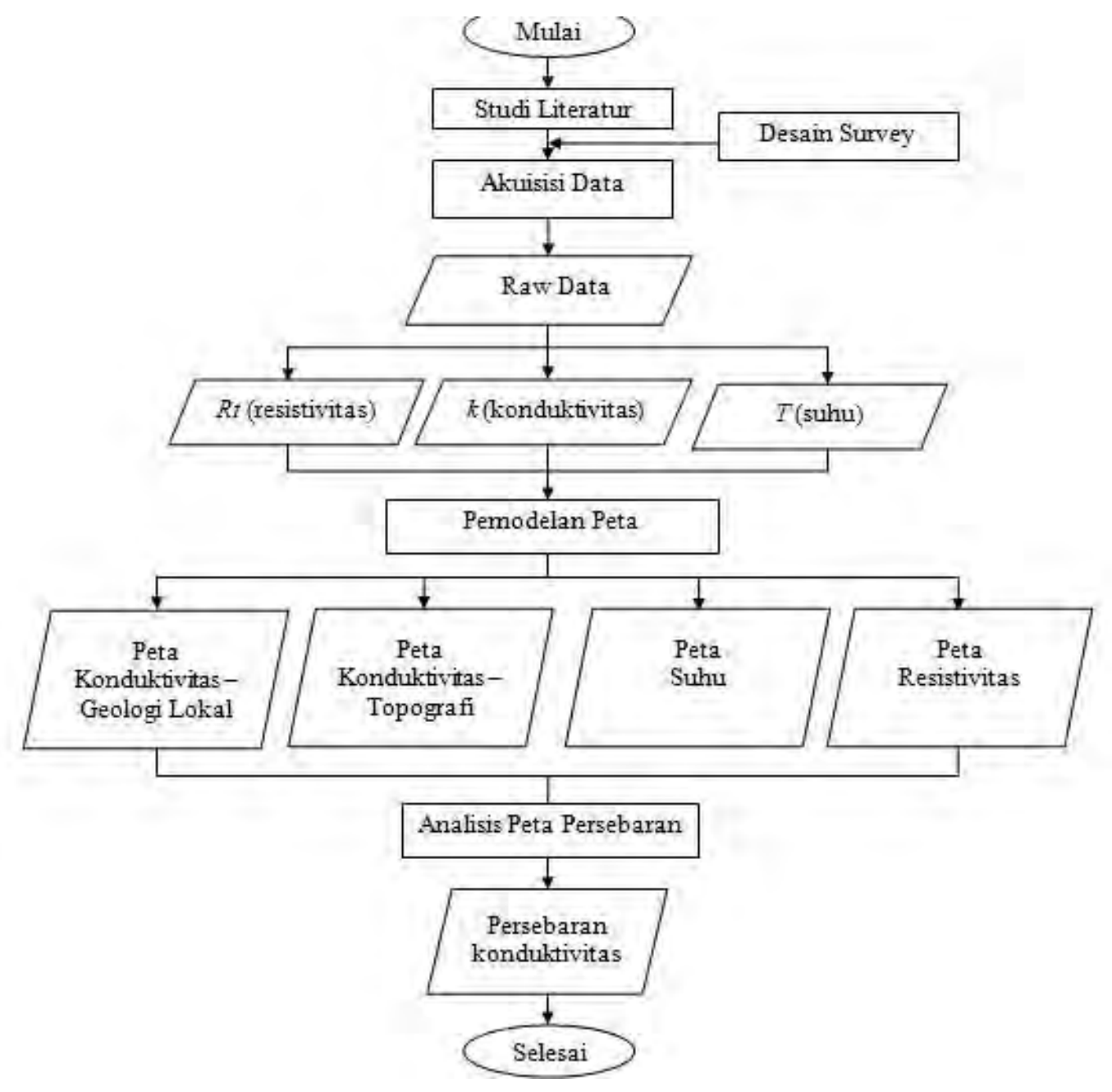

Gambar 5. Diagram alir penelitian. 


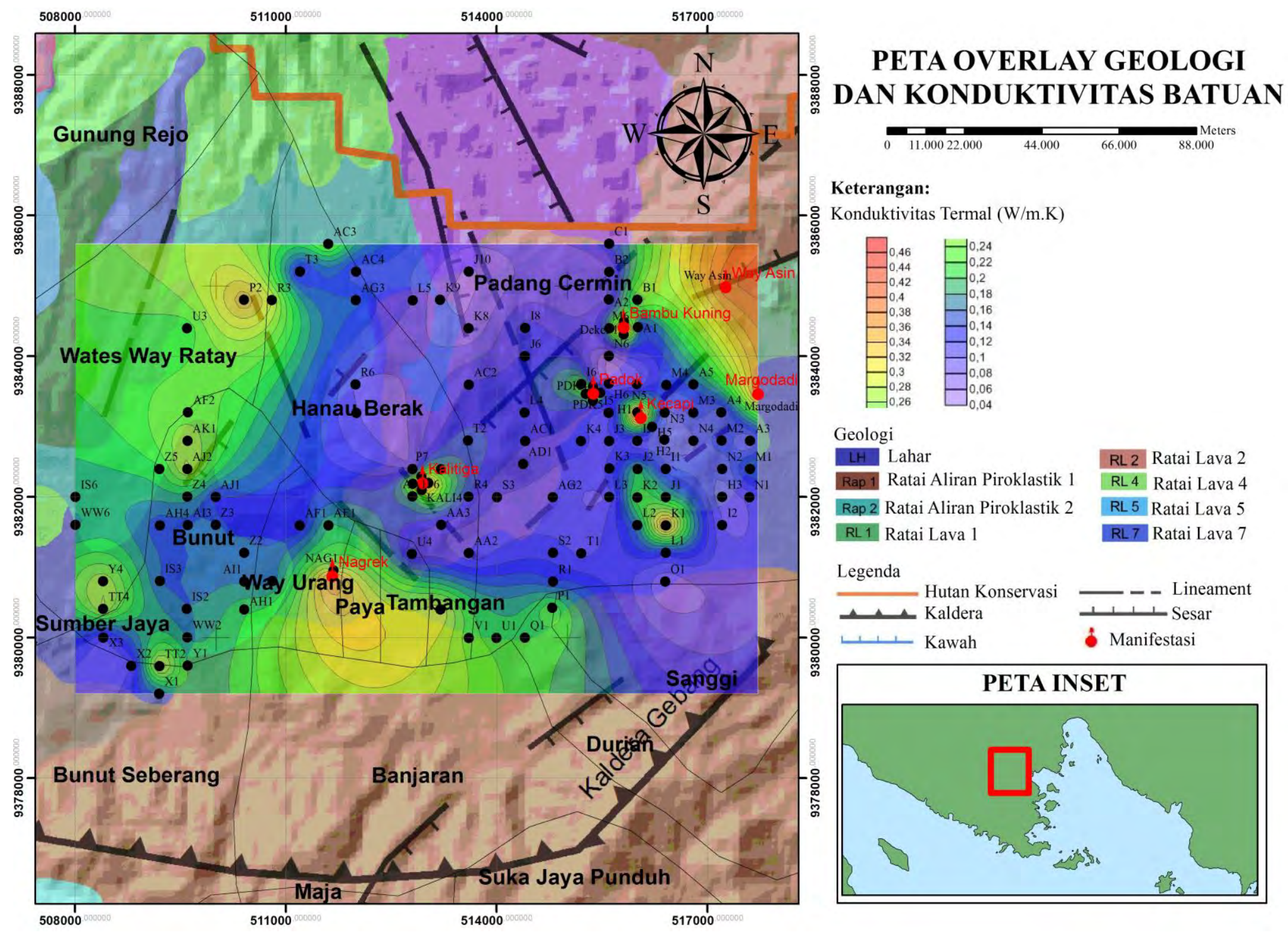

Gambar 6. Peta konduktivitas - geologi lokal. 


\section{PETA KONDUKTIVITAS - TOPOGRAFI}

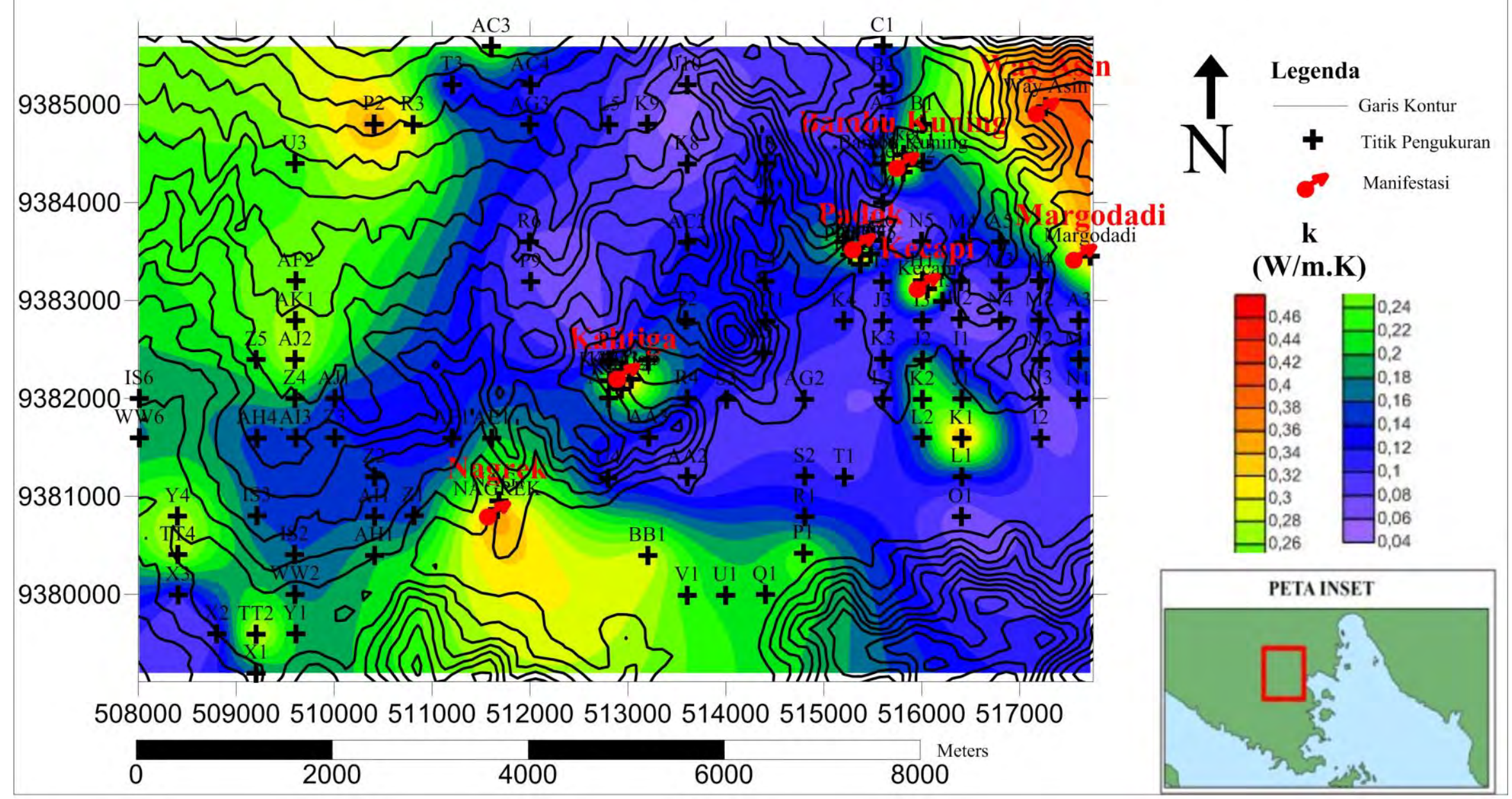

Gambar 7. Peta konduktivitas - topografi. 


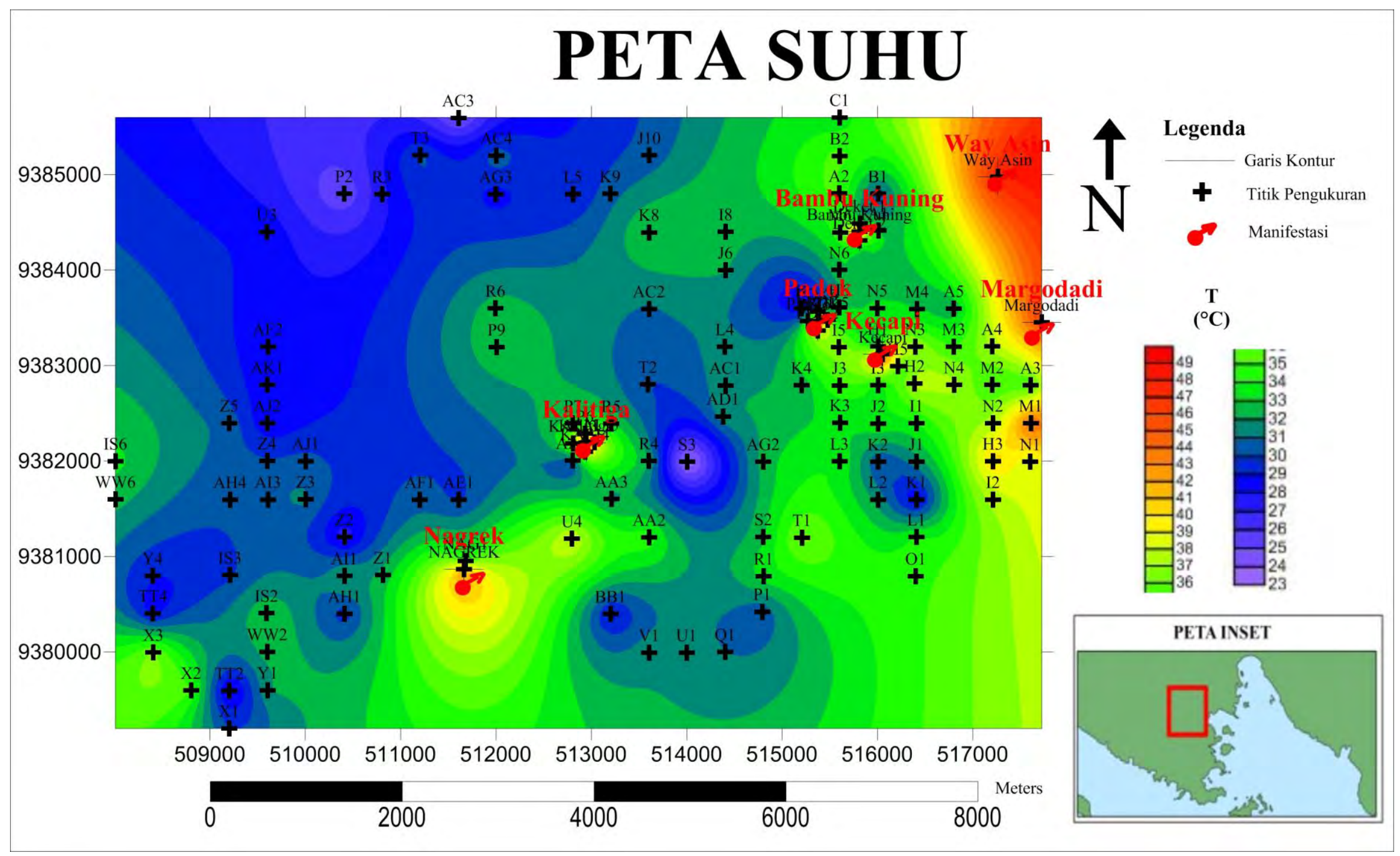

Gambar 8. Peta Suhu. 


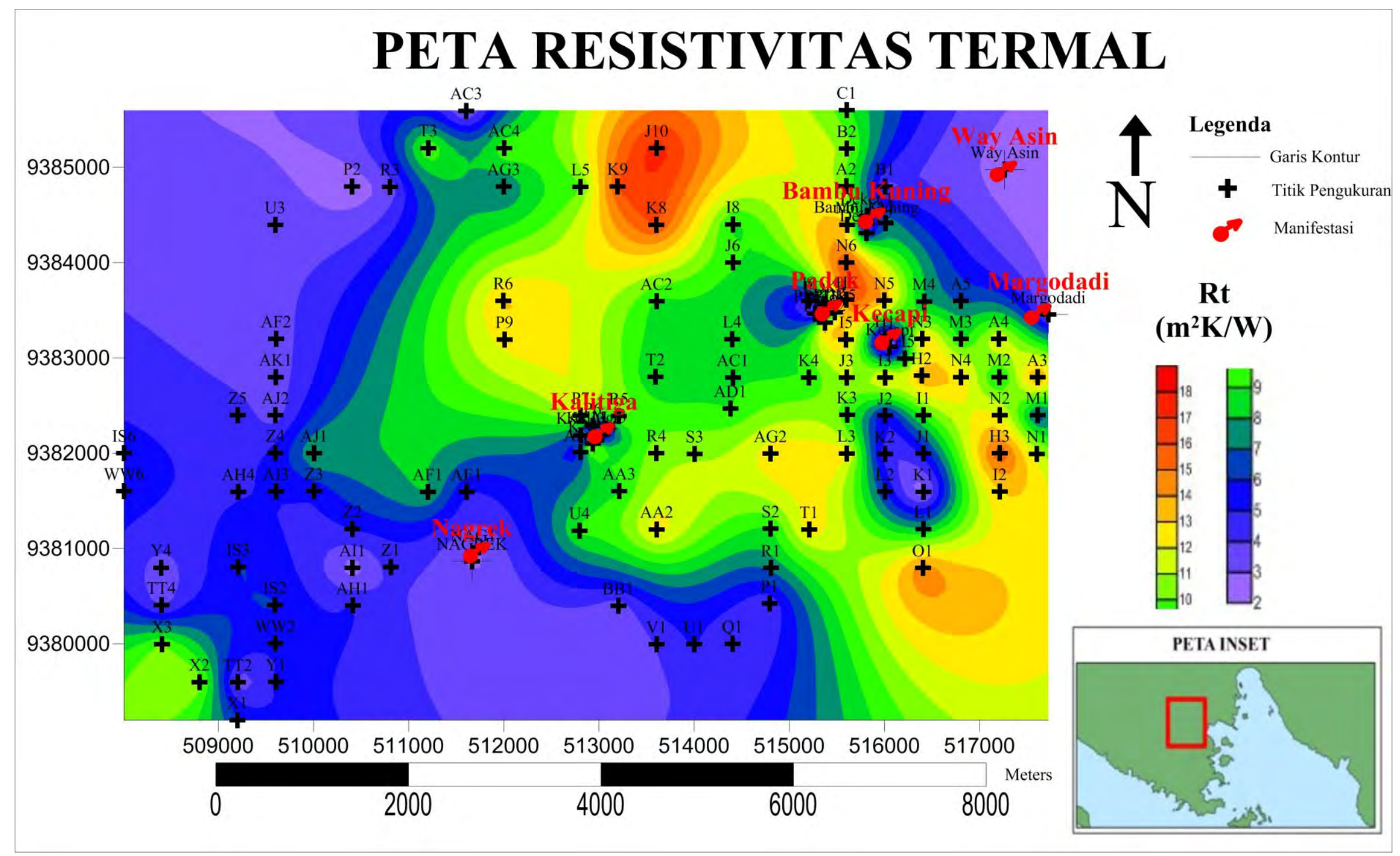

Gambar 9. Peta resistivitas termal. 